\title{
INTERNATIONAL INTEGRATED REPORTING FRAMEWORK: A CASE STUDY IN THE SOFTWARE INDUSTRY
}

\author{
Mădălina Dumitru ${ }^{1}$ \\ Mariana Elena Glăvan ${ }^{2}$ \\ Cătălina Gorgan ${ }^{3}$ \\ Valentin Florentin Dumitru ${ }^{4}$
}

\begin{abstract}
The globalization of the economies, the domination of the multinationals and the development of the capital markets have increased the demand for complex information reflecting commercial, social and environmental context in which organizations operate. Given that financial reporting cannot provide all the information necessary to support decisions, several international organizations work together to achieve the international integrated reporting framework to ensure the connection between the financial and the non-financial information. The objective of our study is to illustrate the principles of the integrated reporting, presented in the International Consultation Draft Framework Integrated reporting Issued in February 2013 and in the 2011 Discussion Paper. Using the content analysis and the case study, we intend to analyze how the company Indra's integrated report is an example of a concise communication in the way in which strategy, governance, performance and future plans of the organization generate value in the short, medium and long term.
\end{abstract}

Key words: integrated reporting, framework, guiding principles, case study

JEL classification: F63, M14

\section{Introduction}

The climate crisis is seen by the United Nations as a bigger crisis than the economic one (Eccles and Krzus, 2010, Colceag et al., 2010, Dascalu et al., 2012). Corporate reporting's answer to this issue is represented by the integrated reporting. Integrated reporting's main result is an integrated report, which includes the financial information, management commentary, governance and remuneration, social and environmental matters, in a way that shows the connectivity between them and explains their impact on the entity's long, medium and short term value creating process (International Integrated Reporting Committee - IIRC, 2011). An integrated report should be prepared in accordance with the International Integrated Reporting Framework (IIRC, 2013a). Not to be confused with simply publishing the contents of an annual report and sustainability report under one cover, integrated reporting aims to provide comprehensive disclosure of a company's finances, governance, strategy and prospects while reflecting the commercial, environmental and social context in which it operates (Dobkowski-Joy and Brockland, 2013).

\footnotetext{
${ }^{1}$ The Bucharest University of Economic Studies, Romania, e-mail: madalina.dumitru@cig.ase.ro

${ }^{2}$ The Bucharest University of Economic Studies, Romania, e-mail: Glavan_EMariana@yahoo.com

${ }^{3}$ The Bucharest University of Economic Studies, Romania, e-mail: CenusaCatalina@yahoo.com

${ }^{4}$ The Bucharest University of Economic Studies, Romania, e-mail: Valentin.Dumitru@soft-expert.info
} 
Integrated reporting is an expression of the "integrated thinking," a reflexion of the management's capacity to monitor, manage and disclose the entire complexity of the value creation process and how it contributes to success in time. Indra considers that communicating this process can help the stakeholders, and particularly the investors, understand both the way a company is performing at present and how it is likely to perform in the future (Indra, 2011). Integrated reporting means also ongoing reporting through the Internet. Integrated reporting adds the discipline that comes from external reporting to the discipline that comes from internal reporting.

Of the 250 world largest companies, 95\% report at some level on sustainability initiative (KPMG, 2011). From the stakeholders' point of view, these reports show in general little linkage between the financial and nonfinancial information. Integrated reports are meant to overcome this issue. The convergence of CSR, sustainable development, and competitive advantage leads to a greater convergence between the interests of all stakeholders, including shareholders. This convergence has implications for a company's external reporting as well (Eccles \& Krzus, 2010).

Markets are not completely efficient, better management practices are always being invented as the world changes, and tough choices are informed, not avoided, by better information and analysis. Integrated reporting is a better management practice that will increase market efficiency and improve resource allocation across all stakeholders in order to create a sustainable society.

Recent research conducted by the IIRC has shown that of the participants in its Pilot Programme, 93\% agreed that moving to an Integrated reporting framework leads to the development of improved cross-functional working processes, breaking down silos between teams, this work contributes to collecting better quality, and 88 percent said that it leads to improvements in business decision making (IIRC, 2013b).

An excessive focus on short-term financial performance must be replaced by a longer-term view which recognizes that a sustainable company depends upon its contribution a sustainable society. The board does not only have obligations on a short-term but also on a longer-term to meet the targets.

There is a lack of standards for the nonfinancial reporting recognized at an international level. IIRC was created in order to supply this lack of standards in the domain of the Integrated reporting.

\section{Brief presentation of the integrated reporting}

Concerns regarding the sustainability date back from 1920s, when Harvard Business School Dean Wallace B. Donham claimed in the article entitled "The Social Significance of Business" that "the development, strengthening and multiplication of socially minded business men is the central problem of business." Social Responsibility was defined by Howard Bowen (called by Archie Caroll the "Father of Corporate Responsibility") in 1953: "It refers to the obligations of businessmen to pursue those policies, to make those decisions, or to follow those lines of action which are desirable in terms of the objectives and values of our society."

The story of integrated reporting started in 1977 with the publication of the book The social audit for management by Clark C. Abt. The term sustainable development was first used in the Bruntland Report issued by the World Commission on Environment and Development in 1987. In Europe, the first sustainability reporting program was the Eco-Management and Audit Scheme (EMAS) implemented in 1995. The program failed and many authors consider that a cause was its non-binding character (Dragomir Voicu, 2012a). In 2000 the Global Reporting Initiative issued its first Sustainability Reporting Guidelines. In June 2000 the European Commission published "EU Financial Reporting Strategy: The Way Forward", which suggested that annual report should not be 
limited only to the financial facet of a business, but also that, "where appropriate, an analysis of environmental and social aspects necessary for an understanding of the company's development, performance or position" should be disclosed (EC, 2000). The suggestion was later included into the 2003 Accounts Modernization Directive, which required: "To the extent necessary for an understanding of the company's development, performance of position, the analysis [in the annual review] shall include both financial and non-financial key performance indicators relevant to the particular business, including information relating to environmental and employee matters" (EC, 2003). The first integrated report was issued by Novozymes, a Danish pharmaceutical company, in 2002. In 2006, EC Directive 2006/46 mandated that all publicly listed companies in Europe had to include a corporate governance statement in their annual report (EC, 2006). In 2010 the filling of integrated reports becomes mandatory for the companies listed at the Johannesbourg stock exchange (King III Report, 2009).

There are many international bodies involved in integrated reporting today working together "to provide for the growing demand for a broad information set from markets, regulators and civil society" (IIRC, 2011): International Integrated Reporting Committee (IIRC), the Global Reporting Initiative (GRI), The Prince of Wales' Accounting for Sustainability Project (A4S), Financial Accounting Standards Board (FASB), International Accounting Standards Board (IASB), Institute of Chartered Accountants in Australia (ICAA), International Federation of Accountants (IFAC), United Nations Global Compact (UNGC), Sustainability Accounting Standards Board (SASB) etc.

The IIRC was founded in 2010 with the mutual support of the A4S and the GRI. In 2011 IIRC released a Discussion Paper regarding the Integrated reporting Framework and launched the Pilot Programme Business Network. In July 2012 the Committee published the Draft Outline of the International Integrated Reporting Framework. On November 26, 2012 the Prototype of the International Integrated Reporting Framework was released, and in February 2013 the International Integrated Reporting Framework Consultation Draft.

The Framework's purpose is to assist organizations with the process of integrated reporting (IIRC, 2013a). In order to do this, the International Integrated Reporting Framework Consultation Draft establishes the Fundamental Concepts (the capitals, the business model, value creation), the Guiding Principles (strategic focus and future orientation, connectivity of information, stakeholder responsiveness, materiality and conciseness, reliability, comparability and consistency), the Content Elements (governance, business model, organizational overview and operating context, opportunities and risks, strategy and resource allocation, performance, future outlook) and the Preparation and Presentation (disclosure of material matters and the materiality determination process, frequency of reporting, time frames for short, medium and long term, reporting boundary, aggregation and disaggregation, involvement of those charged with governance, use of technology and assurance) that govern the Integrated reporting process.

This paper relies on the International Integrated Reporting Framework Consultation Draft issued in February 2013 and on the Discussion Paper (2011), as it was the last one available in the moment of the preparation of the 2011 annual report by Indra. In this article we will emphasize the Integrated reporting guiding principles from which businesses will produce their integrated report. We built our presentation on examples extracted from the integrated report released by Indra in 2011.

\section{The research methodology}

In this article we carried out a content analysis of the integrated reports published by Indra. Content analysis is a method of codifying the text (or content) of a piece of writing into various 
groups (or categories) depending upon selected criteria (Weber, 1988). Following coding, quantitative scales are derived to permit further analysis. Content analysis is "a research technique for making replicable and valid inferences from data according to their context" (Krippendorff, 1980). Content analysis is most often viewed in CSR as "a technique for gathering data that consists of codifying qualitative information in anecdotal and literary form into categories in order to derive quantitative scales of varying levels of complexity" (Abbott and Monsen, 1979). Content analysis is a quantitative and qualitative technique, using qualitative data which are subsequently quantified (Gephart, 2004).

We also use a case study approach. Case study research is a well-established approach, especially in the social sciences (Yin, 2003). Having a widespread application for teaching purposes case studies can be seen as a guide to establishing a frame for data collection in a particular piece of research, thereby seeking to cover contextual conditions which might be relevant for the phenomenon being studied (Herzig et al., 2012). Case studies are particularly suitable for research areas where there are few prior theoretical pieces of literature or empirical research work (Eisenhardt, 1989) and the most appropriate research questions are those asking "how" and "why" (Yin 2003) rather than those requiring broad statistical analysis. Kloot (1997) observes that there have been numerous calls for case studies to be undertaken to study accounting in practice as well as to gain rich descriptions of actual situations (e.g. Kaplan, 1986; Scapens, 1990). In the same time, empirical research in the field of corporate environmental performance should mostly be about creating a context for discussing a firm's commitment to sustainability, rather than modelling irrelevant cross-sectional data to find similarities between incomparable cases (Voicu, 2012b). We expand this judgment in our work to integrated reporting.

The IIRC launched in October 2011 a Pilot Programme Business Network for the companies preparing integrated reports. The list comprises 81 companies. Three of them activate in the software industry: Microsoft, SAP and Indra. Microsoft didn't publish an integrated report in 2011 (it only released a shadow report). Legislation should be informed of what is being learned in practice by innovative companies that are already producing an integrated report. Legislation should be principles-based, on a "comply or explain why not" basis. Early adopters of Integrated reporting will provide useful insights for new products, services or processes, such as software for measuring nonfinancial performance and integrated financial and nonfinancial information systems. We present in this article the Integrated reporting in the case of an industry leader, as we aim to highlight the best practices and lessons. There are other attempts in this direction (Dobkowski-Joy and Brockland, 2013; IIRC, 2013c; IIRC Emerging Database). However, the first two sources present only for some principles some examples for several companies. The IIRC Emerging Database presents the principles for the companies that included their integrated reports in their database. We dare to say that the analysis is not complete. For instance, for the company we selected, Indra, the database highlights only two principles: strategic focus and connectivity. After analyzing the report, we attempt to show examples for all the principles included in the 2011 Discussion Paper. We selected Indra for presentation in this article as it has a four years history in Integrated reporting (while SAP is at its third integrated report), it is one of the few companies disclosing a Sustainability Balance Scorecard in its integrated report and publishes, in our opinion, a "user friendly" integrated report in 2011 (unlike SAP, whose integrated report is very difficult to read). Overall, after reading both reports, the authors considered that this is a more interesting case than the one provided by SAP. 


\section{Presentation of the company: Indra}

Indra is a global company whose origins are related to the company EISA established in Madrid in 1921. A significant moment in Indra's history is the 1933 merger between NISEL and all its subsidiaries and CESELSA resulting Indra Sistemas. The new brand was represented by four companies: CESELSA - Electronics for Defense, ERITEL - Consultancy and IT services, INISEL ESPACIO - Space industry and DISEL - Automation and control.

Nowadays Indra acts in over 128 countries on the five continents and has more than 42,000 employees all over the world, offering products for the following activity sectors: Transport and Traffic, Public Administration, Energy and Industry, Financial Services, Healthcare, Telecom and Media, and Security and Defenced. Indra always had a long term vision and created an image for itself of an innovation-focused company. As an IT company, it has a strong technological base, employs the best talents and offers "leading-edge solutions to blue-chip customers" (Indra Annual Report, 2011).

In the year 1994 Indra América was established in Buenos Aires, the first company established abroad, and in the year 1997 Indra started the development of projects in China. Indra grew by making various acquisitions, of which we mention the technological companies Politec in Brazil and Galilean in Italy in 2011. The company proved a sustained growth since its establishment, becoming the leading technology provider in Spain and one of the leading global multinationals in the segment in Europe and Latin America.

Its corporate responsibility strategy was reassessed starting with the year 2003. This involved launching the Corporate Social Responsibility Master Plan. The Plan included common CSR standards and indicators which were considered that better tracked its performance. The company's approach regarding the sustainability relies on the company's Corporate Social Responsibility vision, which was defined in 2004, following staff consultation and engagement, comprising innovation and knowledge and strong relationships with its stakeholders.

In 2004 Indra was selected to become a member in the UNGC Program. Another important moment in the history of Indra is the year 2006, the company being quoted in the Dow Jones Sustainability Indexes. According to the information published, Indra was included in the Dow Jones Sustainability World Index (DJSWI) and Dow Jones STOXX Sustainability Index (DJSI STOXX) for seven consecutive years. In 2010 Indra becomes world leader in sustainability, leading in the DJSI for the subsector IT Services and Internet. In the same year, the company reaffirms its position as a leader of the global market in the domain of the air traffic management. According to the Annual report 2011 Indra received "Silver Class" from SAM Sustainability Yearbook.

Indra updated its Code of Ethics and Professional Conduct in 2009. Indra had various training initiatives in 2010 and 2011, launching the on-line training program in 2011. In 2011 Indra has been selected was considered one of the "More ethical companies of the world" and received The Garben Award 2011 in the category of "Best Company Training Program."

Indra considers that the solutions and services offered contribute not only to satisfy its customers' needs, but they also help the society and the communities in which it is present, as the company has "a strategy for sustainability", its strengths being "knowledge of our customers, technology competence and the competence of our professionals" (Indra Annual Report, 2008). Its vision is "Enhancing our clients' knowledge to transform their businesses."

Indra grants a special importance to the research, development and innovation activities. In 2008 the company had a network of more than 38 excellence centres. In the same year, Indra became the first European company in its sector, becoming 20 years after its creation, the second largest investor in research and development in its sector in Europe. "Innovation constitutes the 
cornerstone of Indra's strategy," according to the published information "the company invests between $6 \%-8 \%$ of revenue in innovation per year (more than $€ 550 \mathrm{~m}$ in the last three years) and has carried out $270 \mathrm{R} \& D \& I$ projects".

Indra published the first corporate responsibility report in 2003 applying GRI framework and the 2006 report received the first external verification. Corporate Responsibility Report in 2007 was the first one applying the highest GRI level, A+.

For 2008 Indra presented information regarding the performance in the domains economic, social, governance and environment in a single integrated report called "Indra, sustainable growth," which they consider a more realistic presentation of the entity, being able to draw "a joint, global vision of the impact of its activities on all its stakeholders" (Indra Annual Report, 2008).

Starting with 2008, the annual report was prepared according to the AA1000 Accountability standard. In the 2010 Annual Report the Sustainability Balanced Scorecard was included, the performance indicators for the period 2005-2010 being presented for Shareholders, Partners, Employees, Society, Suppliers, Customers, Environment, and Knowledge.

For 2011, the company presents along its annual report the External audit report, the Consolidated annual accounts, Director report, Audit and compliance committee, a summary of the annual report. In 2011, Indra joined the IIRC Pilot Programme Business Network and included in its annual report a few of the fundamental concepts of the integrated reporting and the principles. The next section of our paper presents the way in which the integrated reporting principles are reflected in the 2011 annual report of Indra.

\section{Guiding principles}

The guiding principles included in the IIRC Discussion Paper published in 2011 were:

- $\quad$ Strategic Focus

- $\quad$ Connectivity of Information

- $\quad$ Future Orientation

- $\quad$ Responsiveness and Stakeholder Inclusiveness

- $\quad$ Conciseness, Reliability and Materiality.

Our analysis follows this structure, as it was the last one available in the moment of the publication of the 2011 Annual Report by Indra.

\section{A. Strategic focus}

The role of an integrated report is to provide a view of the organization's strategy and of the way this one influences the organization's ability to create short, medium and long term value. Within it a view on the use of organization's strategy and its effects on different capitals is offered (IIRC, 2013a, 3.2).

Although by the application of the first principle of the framework, the presentation of the organization's strategy and its future results is pursuit, the principle also refers the disclosure of other content. This category could comprise: the presentation of most significant risks and opportunities that arises from "market position and business model", with significant impact on "organization's ability to create value over time" and the justification of business model resilience, the relationship between past and future performance with a list of factors that may change it (IIRC, 2013a, 3.3).

The integrated report is intended to users in order to evaluate the strategy, governance, performance, and the future of an organization. Only to the extent an information is considered 
useful to such estimations, it is included in the integrated report. It is recommended an increased attention in order to avoid stereotypical disclosures (IIRC, 2013a, 3.5).

Strategic focus of an organization and how the organization's business model underpinns the ability to create value, are elements to be well understood by investors (IIRC, 2013c). Given that the objective of integrated reporting is to present such evidence, there is the need for organizations to declare how the quality and availability of capital structures contribute to the strategic role and value creation (IIRC, 2013, 3.4).

\section{Example Indra}

In the case of Indra, the strategic focus is best emphasized by the management's commentary section. In his message, the Chairman discusses about achieving the objectives set, maintaining the profile of profitability and growth, the international trading share of total sales, their strategy of investment in solutions for more dynamic sectors, based on technological innovation, as well as improving their software and service production structure. Its strategy includes the presence in developing markets (such as Latin American), in the same time as keeping an eye on domestic opportunities, making partnerships with other leaders in domain etc. It satisfies the smart solutions demand (e.g. smart cities, digital healthcare, energy efficiency, security) and it provides a greater efficiency of the solutions and Cloud Computing. Its axes of growth correspond to the ones of their sector: geography, intelligence and efficiency, the customer being in the center. For each axis the report presents the achievements for 2011 and the strategy for 2012. The performance and future are presented grouped on solutions and services and on the main markets in which they operate.

The Chairman talks about the main markets (Latin America and Europe, where the entity offers the largest proportion of high added value to its clients $-67 \%$ ). The message also presents the Chairman's opinion on the risks encountered in the entity's domain (e.g. he considers that the solution sector is less vulnerable to the dynamics of price and profit pressure that has affected the service sector so significantly).

Indra presents the objectives for 2011, the actual figures for 2011 and the objective for 2012 . They explain the figures, especially when they disclose negative results. In the section entitled Market Situation and Strategy it describes the economic, environmental, and societal trends. Examples in this regard are the presentation of the asymmetry of the crisis, including the opportunities brought by this phenomenon and by the using the technologies more efficiently, the concentration of the global economic growth in certain economies, the use of technology needed for a sustainable growth. For all these examples the actions of Indra are presented.

They incorporate ESG issues in their management approaches, as they include sections regarding financial performance, environment, employees, human rights, community and society.

\section{B. Connectivity of information}

Seen as a "comprehensive value creation story", the integrated report should present the relationships between various components that contributes significantly to value creation (IIRC, 2013a, 3.7).

In order to assure the connectivity of information, it the connectivity between several elements must be maintained: the content elements; the future, present and past; the capitals; quantitative and qualitative information; financial information and other information. The connectivity of information is increased by complex interdependence relationships between board information, information reported externally and management information, on one side and 
information in the integrated report, information provided by organization through other methods and the information that users acquire from other sources, on the other hand (IIRC, 2013a, 3.10-11).

Unlike traditional reporting, integrated reporting, ensuring completeness of information, provides a more detailed analysis of how the connection is made between the different significant capitals categories for a company and the business model and value creation. At the same time, by integrating information significant risks, performance, opportunities and future strategies are outlined. For many of those who publish an integrated report under IIRC Pilot Programme the connectivity of information consist primarly in connecting people from a variety of internal functions, enabling organizations to better understand the relationship between interdependent business units and eliminate internal barriers to making effective decisions. By connecting information there can be an exchange of opinions with important results related to value creation among employees of an organization and even a more meaningful communication with stakeholders such as investors.

In achieving integrated reporting a very important decision is to include information that meets people's expectations. However, integrated reporting includes both the positives and the negatives for stakeholders, improving transparency (IIRC, 2013c).

In order to overcome various issues they face and to adapt strategies and activities, organizations have to know very well how the decision process influences the creation of value.

In order to improve the completeness of information some organizations use IT applications. Using these applications connecting financial with non-financial information become much easier to achieve. IT applications allow in the same time the interaction between users and data (IIRC, 2013c). In addition, the use of such IT tools that become more and more performing and tailored to organization needs will increase the ability to integrate information.

An important concept is integrated thinking that leads the organization to adopting decisions in an integrate way in order to create value. This is the ability of an organization to identify and intepret the relationships between its operational and functional concepts, on one hand, and the use and the impact on capitals, on the other hand.

Introducing ways to improve the integrated thinking within an organization can improve the integrated thinking process. First, the integration of the information flow in the management's analysis and decision-making is achieved, then in the reporting. Integrated thinking is all the more "embedded into" activities of an organization so as it is more experienced in preparing an integrated report (IIRC, 2013a 3.9).

The information integration and the capability of the integrated report to influence users decisions is improved when it is coherently organized, well presented, with effective navigation opportunities, such as well delimitated abstracts of the sections and cross-references.

In conclusion, by complying with this second principle presented by the framework, integrated report achieves some of its objectives. First, the integrated report exceeds the limits of traditional reporting which is based on historical financial information, explaining how strategy, governance, performance and prospects create value over time. Using the integrated report the intended report users can better understand the factors that influences the future of the organization, its performance and the interdependencies between them. The intended report users can analize and create links between information from the integrated report and information acquired from other sources (IIRC, 2013a, 3.8). 


\section{Example Indra}

In its attempt to improve the quality of its annual report, Indra joined a project which deals with the standardization and dissemination of financial and other data using IT products (IIRC, 2013c).

The entity presents in the same place financial and nonfinancial indicators, including in the Main figures section indicators related to economic (in millions of Euros), social and environmental performance. Another example is the they included in the Business Model section social sustainability (achieved through a software project - Aztec - designed for helping people with disabilities to integrate in the business environment) and economic and social sustainability (SACO Project for training in all types of cyber defense and NEMO\&CODED for dynamic energy efficiency services (efficiency contract)). They present the economic value generated by customers and other net income and its use by the employees, suppliers, society, shareholders, reserves, R\&D investment, depreciation and amortization, other capital providers, in thousands of Euros.

A special section of their report discloses the impacts (economic, environmental, social) of their activity on each category of solutions offered or on stakeholder. Indra connects past, present and future information, quantitative and qualitative facts. It uses environmental criteria in its chain management (for instance, in its pre-selection of the suppliers). Their range of products enriched to include new ones that are used by things developed to be beneficial for the environment (e.g. electric cars, green buildings). They integrate the social and the environmental dimensions (e.g. a Mobility Policy was designed to maximize travel efficiency for the employees). Other examples of connectivity are the presentation of the impact of climate change on the entity or the impact of the entity's investments. The report includes many links to other sources.

However, the report includes mostly narrative description of the connectivity between the financial and nonfinancial information.

\section{Future orientation}

This principle was presented separately in the Discussion Paper, but it is presented along with the strategic focus in the Consultation Draft of the Integrated Reporting Framework.

Forward-looking information is uncertain and thus less accurate than historical information. However, the uncertainty of the future is not a reason to remove such information. In order to intended report users to be able to take decisions using information reported by organizations it is very important that "key estimates and significant assumptions used" and possible risks to be disclosed by the integrated report (IIRC, 2013a 3.6).

In financial reporting because of uncertainties inherent in the activity, many financial statement items can only be estimated, not accurately measured. Estimation process involves professional judgment based on the latest reliable information at their disposal (IAS 8 "Accounting Policies, Changes in Accounting Estimates and Errors".32). When additional information is obtained, initial estimates can be changed. The use of objective estimates is essential in preparing financial statements and should not start from the premise that this may weaken the reliability of the information provided by them. The IASB still recommends disclosure of assumptions and other strains of estimation uncertainty at the balance sheet date to increase the relevance, reliability and understandability of reported information.

\section{Example Indra}

Indra's annual report describes the future challenges, opportunities, and uncertainties, and presents data on past performance along with specific forward-looking targets. The CEO's message 
states that Indra achieved the targets set for 2011: total sales revenue; trading contracts; EBIT; attributable income; net working capital. He presents the international market growth rate; services sector growth; solutions sector decrease. The analysis is made on markets (Telecom \& Media; Energy \& Industry; Public Administrations \& Healthcare; Transport \& Trafic; Financial Services; Security \& Defence). He explains the results, especially when they are negative. In the message are stated the predictions until 2014. The objectives in 2012 are presented in terms of: growth in sales, contracts to sales ratio, recurring EBIT margin, net working capital, net tangible investments, net intangible investments.

They present the key estimates for 2012 and the possible risks, but the entity does not disclose the significant assumptions.

\section{Responsiveness and Stakeholder Inclusiveness}

According to the principle of responsiveness and stakeholder inclusiveness, the quality of the organization's relationships with its key stakeholders can be assessed by analyzing its integrated report. Within the report the degree in which the key stakeholders needs and expectations are identified and met by the organization has to be presented (IIRC, 2013a, 3.13). It was replaced by Stakeholder responsiveness principle in the Consultation Draft.

According to the new international conceptual framework for financial reporting, the central categories of users of the accounting information are investors and creditors, according to the reasoning that the interests and information needs of these groups are similar and cover the interests of all the users of information. The general purpose financial reports first address the present and potential investors, and also the creditors (OB5). In order to answer various informational needs, the IASB's objective is to offer financial information which satisfies the needs of a maximum number of main users. The entities may divulge along the requests corresponding to the common needs useful supplementary information of a certain subset of main users (OB 8). Yet, the general purpose financial reporting cannot offer all the necessary information to creditors and potential and present investors. In order to fundament their decisions, these users have to rely on pertinent information from other sources, for example: general economic conditions and expectations, political events, company and industry prospects (OB 6).

Integrated reporting highlights the importance of continued positive relations with the organization's stakeholders given that value is created not only the organization, but through relationships with others (IIRC, 2013a, 3.14). Stakeholders provide useful information that influences the organization from the economic, social and environment point of view (for example, to identify significant issues, including opportunities and risks, the development and evaluation strategy, etc.) (IIRC, 2013a, 3.15).

Supplying information regarding the quality of the organization's relationships with key stakeholders (customers, suppliers, employees, local communities), and also the entity's answer to satisfy their interests and wishes (decisions, actions, performance) are elements that increase the transparency and responsibility (IIRC, 2013a, 3.16).

Unlike financial reporting, integrated reporting is based on ongoing communication with stakeholders and transparency of internal processes. In this view, the detailed analysis of the needs and expectations of stakeholders is seen as a normal part of business management (IIRC, 2013a, 3.18).

The responsiveness of organizations assumes that the integrated report follows mainly the aspects which significantly contribute to long term favourable results. When referring to this principle we should not expect an integrated report to try to answer all the stakeholders' information 
needs. An integrated report will be a benchmark for other communications, including information compliance, investor presentations, detailed financial reports and sustainability reports for stakeholders who have special information needs. It is expected that such detailed information is placed on-line (IIRC, 2013a, 3.19).

Organization assumes responsibility and responsible use of various forms of capital, whether or not owned by the organization. Through the proper management of capital required or not by regulations, the organization meets the stakeholder's needs that are in line with the concept of value (IIRC, 2013a, 3.21).

\section{Example: Indra}

According to the annual report Indra's stakeholders include: shareholders, suppliers, clients, other partners, the environment, employees, knowledge institutions, and society. For each stakeholder section the 2011 Annual Report presents the main policies and initiatives. The entity uses a range of instruments in order to monitor the relationship with the stakeholders. In 2011, for instance, the entity developed Open Dialogues (Professional Relationship Management) Platform and it launched Internal Communication Master Plan.

Since 2004, the entity launched various programs for different categories of stakeholders (such as the employees, for which it launched Training and Development Programs; clients, aiming a continuous improvement of the relationship with them; suppliers - by launching, for instance the Purchasing Portal). Indra uses Partner Survey to measure partner satisfaction. In 2011 the partner satisfaction has increased 0.1 points.

In the recent years, Indra has been working on increasing the involvement of different stakeholders groups in the design of responses to their needs. It is also making progress in defining a set of monitoring indicators allowing the measurement of the impact and satisfaction generated by the measures developed to solve these needs. In this regard, it is recommended that Indra continue working on this line to extend the methodologies developed throughout the organization (Indra Annual Report, 2011).

They aim to have ambitious and beneficial projects to all of their stakeholders (Indra Annual Report, 2011). The 2011 annual report provides data on positive aspects and areas for improvement, as well as future objectives with respect to each stakeholder, and also the degree of fulfillment of past objectives and commitments.

\section{E. Conciseness, Reliability and Materiality}

„An integrated report should provide concise information that is material to assessing the organization's ability to create value in the short, medium and long term" (IIRC, 2013a, 3.22). In the same time, the information in an integrated report should be reliable (IIRC, 2013a, 3.39), meaning that it should have the following characteristics:

- $\quad$ completeness, neutrality and freedom from error;

- $\quad$ robust stakeholder engagement;

- $\quad$ independent, external assurance.

The principle was split into two principles in the Consultation Draft: Materiality and Conciseness and Reliability.

One can established that information is material if by its importance and relevance can influence the perception of the intended report users regarding the ability of an organization to create value on long, medium or short term. Top management can assess whether an issue is material or not. In this regard, it considers the analysis of the impact that it has or may have on the 
organization's strategy, business model or different types of capital used or influenced, if it is or not substantial (IIRC, 2013a, 3.23). Several companies in the Pilot Programme call for stakeholders to identify significant issues. Some companies are connected to internal and external information to determine significant aspects relevant to development strategy. Materiality analysis serves to identify risks (IIRC, 2013c).

Materiality determination (identification, importance assessment and prioritization of relevant issues) is performed for positive and negative aspects (opportunities or risks, forecasts favorable or unfavorable for the future) and for financial information or other types of information (IIRC, 2013a, 3.24, 3.25). It is important that the process of determining the materiality degree is made at least once a year. Yet, it has to be integrated in the everyday management of the organization, being a piece of the continuous process of management's revision and assessment (IIRC, 2013a, 3.24, 3.25). Are considered relevant issues that have a past, present or future effect on the organization's ability to create value over time, i.e. the organization's strategy, business model or on one or more of the various forms of capital used or influenced. Issues should not be excluded because organizations do not want to address or do not know how to cope with (IIRC, 2013a, 3.26). Not all relevant issues can be considered significant. The criteria on which it is decided that an issue should be included or not in an integrated report, is the one of the importance of its known or potential effect on value. The issue is considered material if, through its importance, has the capacity to influence the assessments substantially (IIRC, 2013a, 3.29).

The material aspects and the materiality determination process must be disclosed within integrated reports to enable users to understand the methodology used (IIRC, 2013a, 3.37). However, the information within the integrated reports should be concise in order to be easily understood and free of redundancy. Although significant information should not be excluded, more detailed information could be presented on Web sites of organizations or through other forms of communication. A balance between comprehensive, concise and comparable information should be considered (IIRC, 2013a, 3.38).

Conciseness, reliability and materiality are guiding principles underlying integrated reporting and determine the content of the integrated report (IIRC, 2011). Many of the respondents to the IIRC's 2011 Discussion Paper (IIRC, 2012) asked for further guidance on the definition of materiality, identification, assessment, prioritization and reporting of the significant issues. The quantitative and qualitative aspects of the materiality have to be understood by the companies and investors.

In the financial reporting information is material if their omission or wrong presentation could influence the economic decisions of the users of the specific reporting entities. In the context of such an individual entity, the materiality level is characteristic to the relevance, relying on the nature or size, or both, of the items to which the information refers. IASB cannot determine from the beginning what can be significant in a certain situation and cannot establish a uniform materiality degree either (QC 11).

For the integrated reporting, applying the materiality may be different from applying the same principle in financial reporting; reflecting differences in the views of stakeholders about what is significant. Many investors have required annual reports to clearly identify material risks and the financial and strategic implications of non-financial issues. Many organizations in the Pilot Programme established connections with the interested parties in order to consider their needs, interests and expectations to determine significant aspects. Integrated reporting represents the ability of the organization to understand these needs and the degree in which they are considered. 
The reliability of information is "affected by its completeness, neutrality and freedom from error". Yet, in the integrated report it is expected that it is not always possible that all the information fulfils these characteristics in all the aspects. If possible, the entities have to pursue the maximisation of these qualities (e.g., by ensuring that any negative matters are as faithfully reported as positive ones) (3.40). (IIRC, 2013a, 3.40). The reliability can be improved by the implication of the stakeholders in order to establish, mainly, "the completeness and neutrality of information".

The new international financial reporting conceptual framework replaces reliability with the faithful representation, which reflects a greater concern for economic substance and less for statistical accuracy (Gîrbină, 2009). For financial information to meet the requirement of fair representation, it „must meet the following characteristics: to be complete, neutral and free of material errors" (QC 12).

By applying professional judgment, the management of the organization decides whether the information is ,sufficiently reliable so as to be included in the integrated report”. Within this report sometimes it may be necessary to be presented the ways in which the credibility of information is assured (IIRC, 2013a, 3.41). When because of reliable data and juridical restrictions material information cannot be presented, the integrated report has to indicate the information that was omitted, the reason of the omission and the efforts made to obtain unavailable data (IIRC, 2013a, $1.15)$.

All the material information have to be included in an integrated report, whether they are positive or negative. The information reported by the organizations within the same industry may be presented as an example for the users when they want to be sure that the organization identified and reported all the material aspects (IIRC, 2013a, 3.42). In the context of establishing the completeness of an integrated report, the organization has to analyze the following: cost/benefit ratio, the competitive advantage, the forward looking information. Even though sometimes these characteristics are considered responsible for the omission of significant information, in each case their observance makes the reported information fulfill the objective of the integrated reporting (IIRC, 2013a, 3.43). The selection and presentation of information does not involve the existence of subjectivity in a neutral integrated report. The information cannot be manipulated in any way to influence the way it is received by the users, favorably or unfavorably. The organization applies several methods to assure the neutrality of information offered in the integrated report (for instance, the selection of presentation formats that couldn't be accused of negatively influencing the decision of the intended report users; ,giving equal weighting to both increments and decrements to the capitals, both strengths and weaknesses of the organization, both positive and negative performance" etc.) (IIRC, 2013a, 3.56).

Freedom from error assumes that the information presented doesn't include errors or omissions and that the selection and application of the process by which the information is reported was made without errors. Yet, the information reported cannot be perfect from all the points of view (IIRC, 2013a, 3.57). When estimations are needed, the nature and the limits of the estimation process are explained. The organization has to reduce through processes and controls "to an acceptably low level the risk that reported information contains a material misstatement" and to remove the possibility that misstatements are included in the integrated report. Through such an approach, the organization is assured that the integrated report is free from error (IIRC, 2013a, 3.58).

In the financial reporting, a neutral description is unbiased in the selection or presentation of the financial information. Neutral information does not necessarily mean information with no aim 
or influence on behavior. On the contrary, relevant financial information is, by definition, capable to influence the users' decisions (QC 14).

\section{Example: Indra}

Unlike many companies included in the IIRC Plot Programme, since 2007, Indra conducted a materiality analysis each year. The materiality was established considering issues included in the sustainability reports prepared by other IT and Defence companies; press reports, but mainly the ones that could negatively impact on the entity; factors that are considered relevant by socially responsible investors, employees, suppliers and customers; the opinions of opinion leaders.

Indra developed quarterly CSR Committees that jointly with the different areas of the company, are intended to prioritize and establish deadlines and responsibilities of the actions contained in the Corporate Responsibility and Reputation Master Plan. The ESG materiality issues are in line with the financial information. Thus, Indra selects non-financial factors that it considers to be material to its business model and strategy from a sustainability scorecard with quantitative data and indicators on its main business impacts (IIRC, 2013c).

Indra's Annual Report summarizes material issues, KPIs and future targets. However, the size of the report (275 pages) is quite big, considering that the company discloses the financial statements and the notes in a separate report.

Regarding the reliability, both the financial information and the environmental, social and governance information contained in the integrated report are audited (verified) by independent third parties. The results of the audit (verification) are presented in a special section in the report. The integrated audit has the same benefits as a rigorous financial audit, ensuring the quality and integrity of a company's internal measurement and control systems (Eccles \& Krzus, 2010).

\section{Conclusions}

The integrated report provided by Indra for 2011 is a good example for other entities interested in applying the integrated reporting, as the company already has a history in integrated reporting and acts in a business in which it is interested in knowing the best practices in order to provide support for its customers. They don't use too many chart in their annual report, but they use plenty of tables and colors to emphasize the important parts of their report. The management messages address the shareholder, not the stakeholder and they only make reference to the financial reporting. The company is part of IIRC, GRI, UNGC, everything disclosed in the report has been verified externally, offering a high degree of reliability. You cannot download from the website only certain parts from their report. The report provides illustrations for each of the principles included in the IIRC Discussion Paper.

Indra's 2011 annual report is also included in the IIRC Emerging Integrated Reporting Database. However, the database provides examples only for three principles: strategic focus and future orientation, stakeholder responsiveness, materiality and conciseness. Our contribution is the attempt to provide examples for all the principles included in the last version of the integrated reporting framework. We also analyzed the principles in relation with the financial reporting qualitative characteristics. As the integrated reporting is at the beginning and the literature is very poor in this regard, we consider that we made a contribution for anyone interested in this domain.

Any mandate for integrated reporting is not a binary act, no more than it can be said that a company is or is not practicing integrated reporting. Integration occurs in degrees (Eccles and Krzus, 2010) and Indra, with its 2011 Annual Report provides, in our opinion, a good example for 
the companies wishing to experience integrated reporting. Yet, the analysis presented within this paper was rather subjective; it is the result of the authors' interpretation; we don't consider our conclusions as statistically significant or as representative for all the integrated reports.

\section{References}

1. Abbott W., Monsen R., 1979. On the measurement of corporate social responsibility: self-reported disclosure as a measure of corporate social involvement, Academy of Management Journal, Vol. 22, pp. 501 - 515

2. Colceag F., Caraiani C., Dascalu C., Lungu C.I., Guse R.G., 2010. Conceptual modeling of sustainable performance related to social and environmental accounting, ISI Proceedings of the 5th Conference on Accounting and Management Information Systems (AMIS)

3. Dascălu C., Caraiani C., Gu $\square$ e G. R., Lungu C. I., 2012. Environmental-oriented management strategy, African Journal of Business Management, 6(18), pp. 5829 - 5839

4. Dobkowski-Joy A., Brockland B. 2013. Innovation and experimentation in the merging of ESG and financial disclosure, available online at http://framework-llc.com/wpcontent/uploads/2013/03/FrameworkLLC_StateOfIntegratedReporting__ 0313.pdf, accessed March, 2013

5. Dragomir V.D. 2012a. Sustainability reporting: a case for corporate accountability, Bucureşti, ASE Publishing House

6. Dragomir V.D., 2012b. The disclosure of industrial greenhouse gas emissions: a critical assessment of corporate sustainability reports, Journal of Cleaner Production, 29-30, pp. 222-237

7. Eccles R., Krzus M., Rogers J., Serafeim G. 2012. The Need for Sector-Specific Materiality and Sustainability Reporting Standards, Journal of Applied Corporate Finance, Volume 24, Number 2, pp.65-71

8. Eisenhardt K.M., 1989. Building theorie from case study research, Academy of Management Review, 14, pp. 532-550

9. European Commission, Communication from the Commission to the Council and the European Parliament: EU Financial Reporting Strategy: the way forward, available online at http://eur-lex.europa.eu/LexUriServ/LexUriServ.do?uri=COM:2000:0359: FIN:EN:PDF, accessed February, 2013

10. European Council and Parliament Directive no. 2003/51/EC (Accounts Modernization Directive), available online at http://eur-lex.europa.eu/LexUriServ/ LexUriServ.do?uri=OJ:L:2003:178:0016:0022:en:PDF, accessed February, 2013

11. European Council and Parliament Directive no. 2006/46/EC, available online at http://eur-lex.europa.eu/LexUriServ/LexUriServ.do?uri=OJ:L:2006:224:0001:0007:EN: PDF, accessed February, 2013

12. Gephart R.P., 2004. Normal risk: Technology, sense making, and environmental disasters, Organization \& Environment, Vol. 17, pp. 20-26

13. Gîrbină M., 2009. Strategii şi politici de gestiune a riscurilor şi incertitudinilor, Bucharest

14. Herzig C., Viere T., Schaltegger S., Burritt R., 2012. Environmental management accounting. Case studies of South-East Asian companies, Routledge

15. IASB, 2010. The Conceptual Framework for Financial Reporting, available online at http://www.ifrs.org/IFRSs/Pages/IAS.aspx, accessed October 2012 
16. International Integrated Reporting Committee, 2011. About IR, available at $\mathrm{http}: / / \mathrm{www}$.theiirc.org/about/, accessed January, 2013

17. International Integrated Reporting Committee, 2012. Summary of Responses to the September 2011 Discussion Paper and Next Steps, http://www.theiirc.org/wpcontent/uploads/2012/06/Discussion-Paper-Summary1.pdf, accessed October, 2012

18. International Integrated Reporting Committee, 2013a. International Integrated reporting Framework Consultation Draft, available online at http://www.theiirc.org/wpcontent/uploads/2013/02/WG-20130212-ITEM-4-FRAMEWORK-2-

CONSULTATION-DRAFT-1.pdf, accessed February, 2013

19. International Integrated Reporting Committee, 2013b. Building the Business Case for Integrated Reporting, available at http://www.theiirc.org/resources-2/otherpublications/building-the-business-case-for-integrated-reporting/, accessed February, 2013

20. International Integrated Reporting Committee, 2013c. Pilot Programme 2012 Yearbook, http://www.theiirc.org/resources-2/other-publications/2012-yearbook/, accessed February, 2013

21. Kaplan R.S., 1986. The role for empirical research in management accounting, Accounting, Organizations and Society, 11, pp. 429-452

22. King III Report, 2009. King Code of Governance 2009, available online at http://www.ecgi.org/codes/documents/king3.pdf, accessed February, 2013

23. Kloot L., 1997. Organizational learning and management control systems: responding to environmental change, Management Accounting Research, 8, pp. 47-73

24. KPMG, 2011. KPMG International Survey of Corporate Responsibility Reporting 2011, pp. 7, available online at http://www.kpmg.com/Global/en/IssuesAndInsights/ ArticlesPublications/corporate-responsibility/Documents/2011-survey.pdf, accessed March, 2013

25. Krippendorff K., 1980. Content Analysis: An Introduction to its Methodology, London, Sage

26. Scapens R.W., 1990. Researching management accounting practice: the role of case study methods, British Accounting Review, 22, pp. 259-281

27. Weber R., 1990. Basic Content Analysis, 2nd Ed., Sage University Paper Series on Quantitative Applications in the Social Sciences No 49, Newbury Park, Sage

28. Yin R.K., 2003. Case study research, Thousand Oaks, Sage

29. http://www.indracompany.com/en/accionistas/memoria-y-cuentas-anuales, accessed February, 2013 